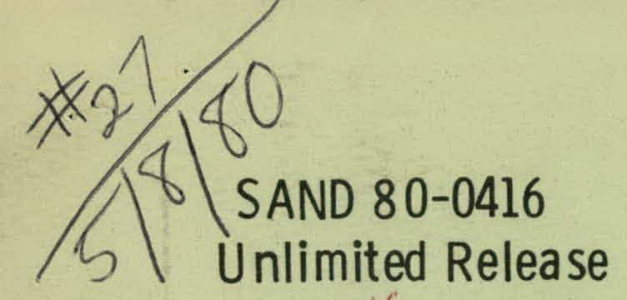

\title{
STORED ENERGY OF GAMMA-IRRADIATED WIPP SALT
}

\section{MASTER}

M. Moss

Prepared by Sandia Laboratories, Albuquerque. New Mexico 87185

and Livermore. California 94550 for the United States Department of

Energy under Contract AT $(29-1)-789$

March, 1980 


\section{DISCLAIMER}

This report was prepared as an account of work sponsored by an agency of the United States Government. Neither the United States Government nor any agency Thereof, nor any of their employees, makes any warranty, express or implied, or assumes any legal liability or responsibility for the accuracy, completeness, or usefulness of any information, apparatus, product, or process disclosed, or represents that its use would not infringe privately owned rights. Reference herein to any specific commercial product, process, or service by trade name, trademark, manufacturer, or otherwise does not necessarily constitute or imply its endorsement, recommendation, or favoring by the United States Government or any agency thereof. The views and opinions of authors expressed herein do not necessarily state or reflect those of the United States Government or any agency thereof. 


\section{DISCLAIMER}

Portions of this document may be illegible in electronic image products. Images are produced from the best available original document. 
Printed in the United States of America

Available from

National Technical Information Service

U.S. Department of Commerce

5285 Port Royal Road

Springfield, VA 22161

Price: Printed Copy $\$ 4.00 ;$ Microfiche $\$ 3.00$ 
SAND $80-0416$

STORED ENERGY OF. GAMMA-IRRADIATED WIPP SALT*

M. Moss

Sandia National Laboratories

Albuquerque, New Mexico 87185

\section{Abstract}

Samples of WIPP salt exposed at $363 \mathrm{~K}$ to gamma radiation from a co 60 source were annealed at constant rates of heating in a differential scanning calorimeter in order to release the energy stored. Radiation doses were 2.2, 5.4, $8.2,11$ and $13 \times 10^{9} \mathrm{rad}$, and temperature scans were conducted from room temperature to $800 \mathrm{~K}$. The specific stored energy-dose relationship deduced from" $80 \mathrm{~K} / \mathrm{min}$ scans could be only approximately established due to the extreme variability of the specific energy in samples of a given dose. This variability probably results from unequal amounts of impurities in the $10-25 \mathrm{mg}$ samples required for the calorimeter. The energy-dose relationship is best described empirically by $1 \mathrm{n} \mathrm{Q}_{0}(\mathrm{cal} / \mathrm{y})=(-40.6 \mp 2.6)+(1.84 \pm 0.12) \ln \mathrm{f}(\mathrm{rad}) \cdot$ Temperature scans of $10,20,40$ and $80 \mathrm{k} / \mathrm{min}$ were performed to determine the activation energy E.of. the annealing process. For the four more highly dosed samples, $E=31.1 \pm 5.6 \mathrm{kcal} / \mathrm{mole}$. Based upon criteria established elsewhere, there appears to be no danger of the stored energy being released quickly in a nuclear waste repository. of bedded salt, nor could serious consequences result from such a release by some unforeseen mechanism. 
Table of Contents

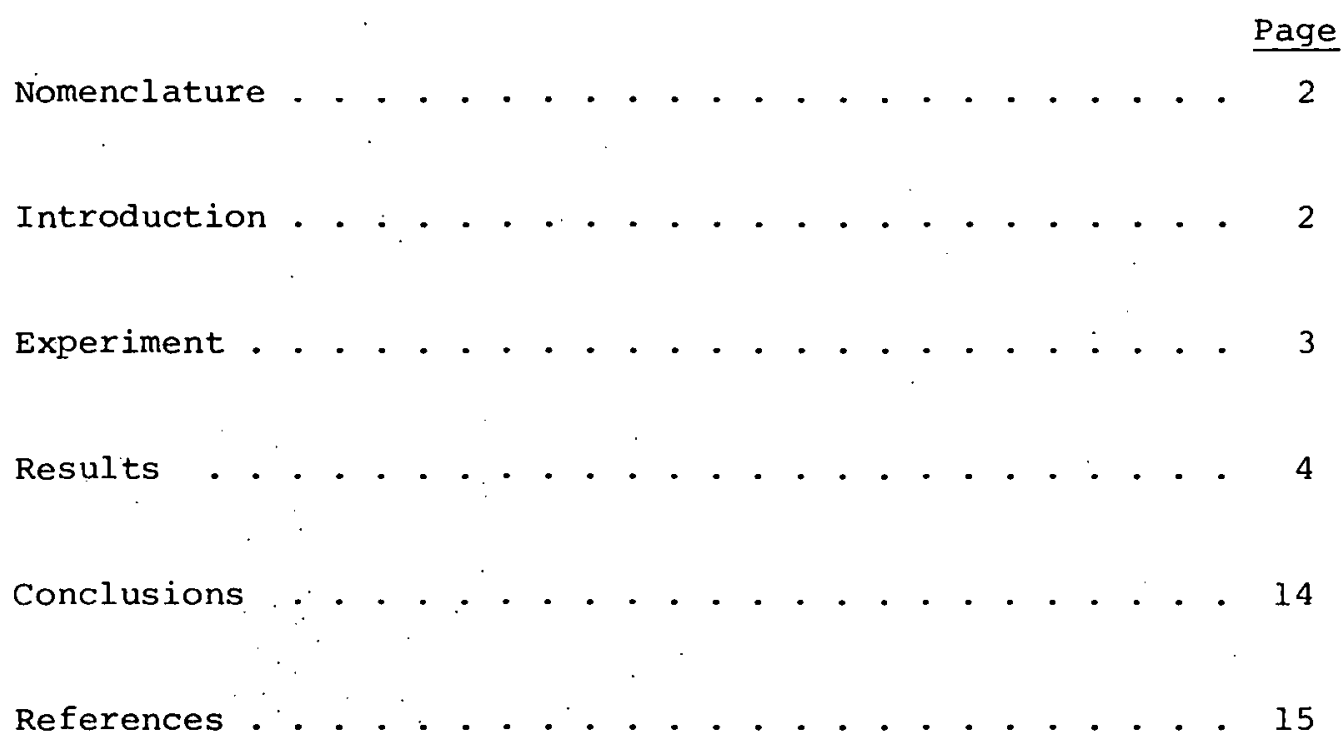




\section{Nomenclature}

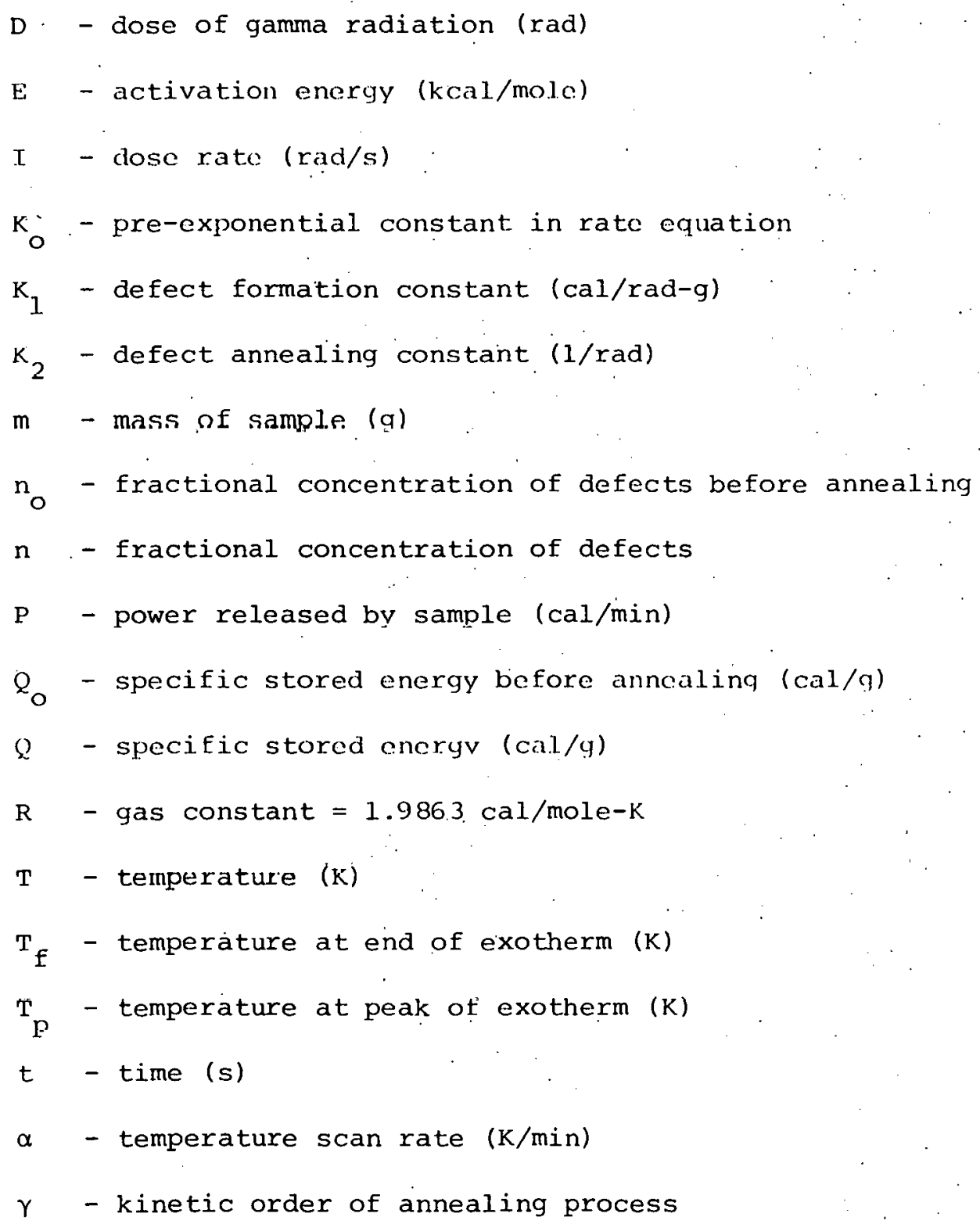

\section{Introduction}

The gamma irradiation of salt in a proposed bedded-salt nuclear waste repository could produce various kinds of damage to the salt, such as the displacement of atoms and the formation of other point defects. ${ }^{1-3}$ This results in energy being accumulated and the plasticity of the crystal being reduced. 
It is important to assess the effects of the release of this stored energy on the integrity of the repository. Given the expected temperatures in the vicinity of waste canisters, one would like to predict how rapidly the defects in the irradiated salt will release their energy. Should there be an abrupt and large exothermic reaction, damage to the canisters and the salt might occur. Cracks in an embrittled material might permit brine and, hence, radionuclide movement.

Measurements of stored energy in alkali halides have been made by various calorimetric methods. ${ }^{1-7}$. Differences are noted between pure NaCl and the salts mined from various deposits which generally contain several percent of assorted impurities. This study is of material from the Carlsbad, New Mexico area associated with the proposed waste Isolation Pilot Plant (WIPP). 8 The salt samples were obtained from a core taken from the 741.3 and $796.0 \mathrm{~m}$ levels of the ERDA-9 drill hole, both within the same geological formation. The materials from these levels probably do not differ any more in composition than cores taken from adjacent locations at the same level. This, however, is a presumption and is not based on chemical analysis.

The mechanical properties and thermoluminescence of irradiated salt are also being measured at Sandia National Laboratories by G. W. Arnold.

\section{Experiment}

The WIPP. salt used in this experiment was approximately $97 \% \mathrm{NaCl}$, the balance being clay, anhydrite $\left(\mathrm{CaSO}_{4}\right)$, and lesser quantities of minerals containing potassium, strontium and magnesium. The irradiation of the salt was conducted by G. W. Arnold of Sandia National Laboratories in its co gammairradiation facility. Source intensity of the $1.3 \mathrm{MeV}$ radiation was 
approximately.10 Mrad/h, and samples were exposed to $2.2,5.4,8.2,11$ and 13 $\times 10^{9}$ rad. The last dose represents 7.7 wecks of irradiation. All doses are considered accurate to within $15 \%$. Temperature of the salt durind irradiation was approximately $363 \mathrm{~K}$. The $2.2 \times 10^{9}$ and $1.3 \times 10^{9}$ rad samples were from the. $796.0 \mathrm{~m}$ level of the ERDA-9 drill hole, the others coming from the $741.3 \mathrm{~m}$ level.

All post-irradiation samples were of a dense violet color. Upon heating to 800. $\mathrm{K}$, the color disappeared leaving the crystals transparent and light gray . Annealing was done in a Perkin-Elmer differential scanning calorimeter, Model DSC-2. For stored energy measurements, samples weighing 10-25 mg were hermetically scaled in gold capsules, and heated at $80 \mathrm{k} / \mathrm{min}$ from room temperature to $800 \mathrm{~K}$, well above the temperature required to release all stored energy.

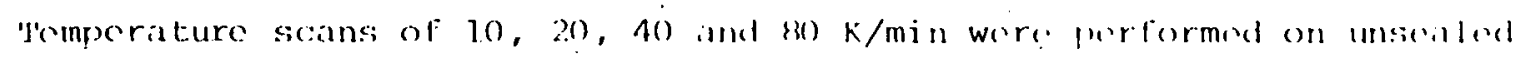

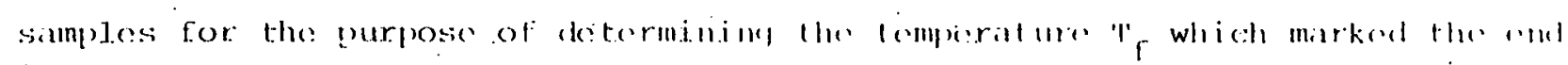
of an energy release. The fact that the gold capsules were unscaled did not affect the value of $\mathrm{T}_{\mathrm{f}}$. All runs were performed with the samples in flowing dry argon and in total darkness since light enhances the annealing process. ${ }^{2}$

\section{Results}

Figure 1 is the trace of a temperature scan of $80 \mathrm{k} / \mathrm{min}$ for WIPP salt with $D=11 \times 10^{9}$ rad. $P$ is the power released by the sample as a function of temperature T. This scan rate typically produced one well-defined exotherm peaking at a temperature $\mathrm{T}_{\mathrm{p}}$ around $600 \mathrm{~K}$ for the $2.2 \times 10^{9}$ rad samples, the peak increasing to $660 \mathrm{~K}$ for $13 \times 10^{9} \mathrm{rad}$. Slower scans gave broader and lower exotherms which were more difficult to interpret and, therefore, not used in determinations of stored cnergy.

Others have noted more than one event, each associated with the annealing of a particular defect. 4 rt was not the purpose of this study to clucidate 
<smiles>C1=C2C=C2C1</smiles> 
the various mechanisms of the annealing process, but rather to determine the total energy release. Energy releases peak and end at temperatures which depend upon heating rate (Table I). The heating rates here are generally higher than those used by others because the exotherms could be more clearly identified. Table I. Temperatures at Peaks $\left(\mathrm{T}_{\mathrm{p}}\right)$ and Ends $\left(\mathrm{T}_{\mathrm{f}}\right)$ of Exothermic Reactions in
WIPP Salt.

$$
T_{p}(K) \text { is on top, } \dot{T}_{f}(K) \text { is below it. }
$$

Dose, D $\left(10^{9} \mathrm{rad}\right)$ Temperature Scan Rate, $\alpha(\mathrm{K} / \mathrm{min})$

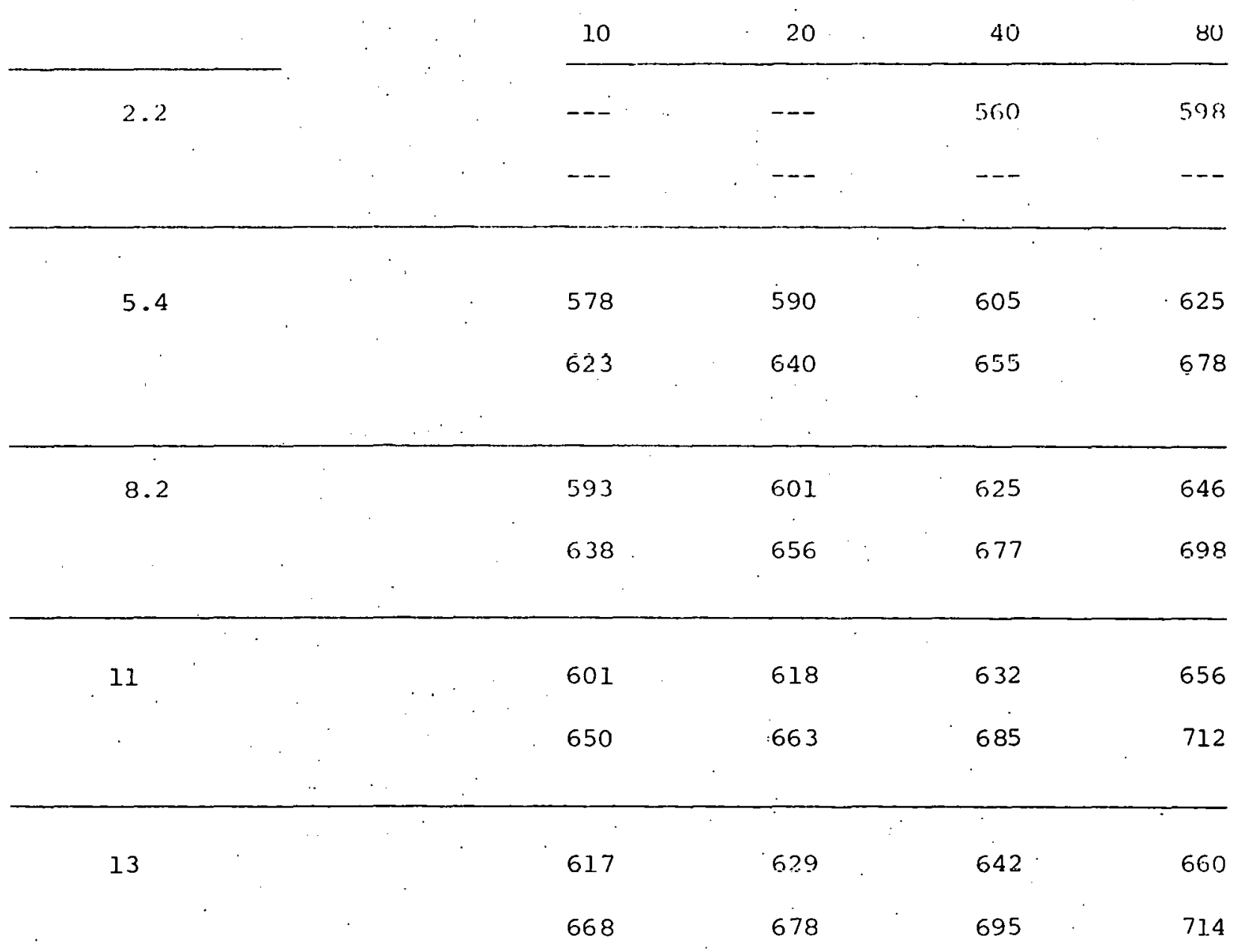


The specific stored energy $Q_{0}$ found from a trace like $F i g .1$ is

$$
Q_{0}=\int \frac{\operatorname{PdT}}{\mathrm{m} \alpha}
$$

the integration being taken over the entire area of the exotherm; $m$ is the mass of the sample and $\alpha$ is the heating rate. Jenks and Bopp ${ }^{3}$ propose a semitheoretical relation for the time rate of change of $Q_{0}$.

$$
\frac{d Q_{O}}{d t}=K_{1} I-K_{2} I Q_{O}
$$

in which $I$ is the dose rate, and $K_{1}$ and $k_{2}$ are the defect formation and annealing constants, respectively. Equation (2) expresses the rate of increase of stored. energy as a balance between the production and annihilation rates of defects, the former being proportional to the dose rate, and the latter to the dose rate and stored energy.

The integral of Eq. (2),

$$
Q_{0}(t)=\frac{K_{1}}{K_{2}}\left(1-e^{-K_{2} D(t)}\right)
$$

describes the specific stored energy where the dose $D(t)=\int_{0}^{t} I(\tau) d \tau$. In this experiment $I$ is a constant and, consequently, $D(t)=I t$.

Figure 2 shows the data; the levels of $Q_{0}$ agree generally with Jenks and Bopp's. ${ }^{3} Q_{0}$ as a function of $D$ (solid lines) for three choices of the parameters $k_{1}$ and $k_{2}$ is also shown. The curves $A, B$ and $C$, represent $K_{2}=10 \times 10^{-11}$, $15 \times 10^{-11}$, and $20 \times 10^{-11} \mathrm{rad}^{-1}$, respectively, with $\mathrm{k}_{1}=1.4 \times 10^{-9} \mathrm{cal} / \mathrm{rad}-\mathrm{g}$ for all three. None of these curves appears to represent the data adequately. 


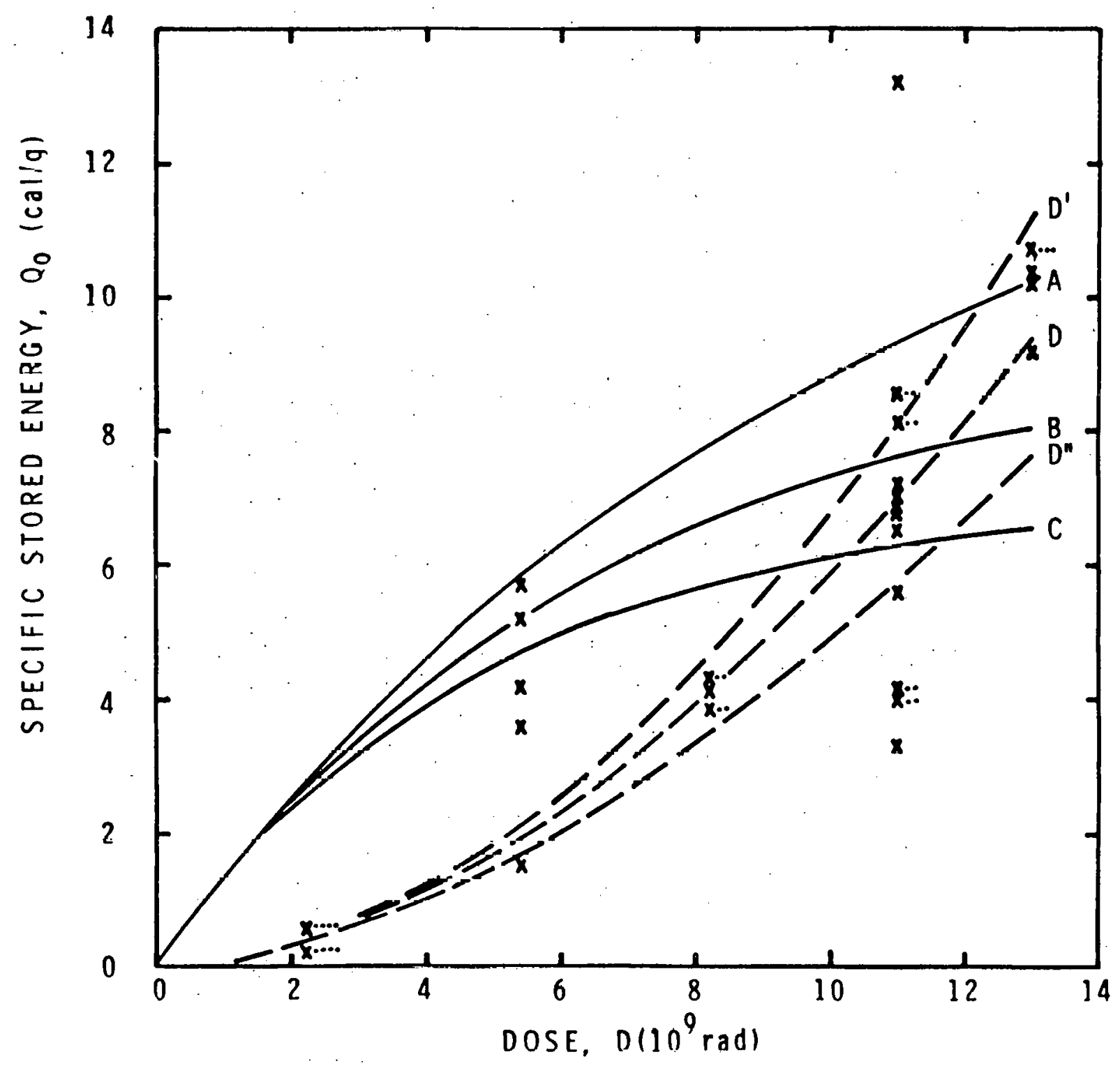

Figure 2. Specific stored energy vs. dose in WJPl salt. Where datum points overlap, the number. of such points is indicated by the dots to the richt of the cross... In Eq. (3), $\mathrm{K}_{1}=1.4 \times 10^{-3} \mathrm{cal} / \mathrm{rad}-\mathrm{g}$ and $(\mathrm{A}) \mathrm{K}_{2}-10 \mathrm{x}$ $10^{-11} \mathrm{rad}^{-1}$, (B) $\mathrm{K}_{2}=15 \times 10^{-11} \mathrm{rad}^{-1}$, and (C) $\mathrm{K}_{2}=20 \times 10^{-11} \mathrm{rad}^{-1}$ (solid curves). For the dashed curve (D), $\ln \varrho_{\mathrm{O}}(\mathrm{cal} / \mathrm{g})=-40.6+1.84$ $\operatorname{lnD}(\mathrm{rad})$. Curves $\left(D^{\prime}\right)$ and $\left(D^{\prime \prime}\right)$ represent the standard deviation (see text). 
$\mathrm{K}_{1}$ is the same as Jenks and Bopp's value. ${ }^{3}$ For pure Harshaw salt irradiated at $368 \mathrm{~K}$, they found $\mathrm{K}_{2}=4.4 \times 10^{-11} \mathrm{rad}^{-1}$.

My data were empirically fitted by least squares to the equation 1 no $($ cal/g) $=$ $a+b$ In $D(r a d)$, in which $a=-40.6 \mp 2.6$ and $b=1.84 \pm 0.12$, the second number in each case being the standard deviation. The dashed line D in Fig. 2 represents this relation and has no theoretical basis. The dashed lines $D^{\prime}$ and $D^{\prime \prime}$ represent the probable limits of uncertainty given by $d Q_{0}=Q_{0}(d a+d b \ln D)$, where da and $\mathrm{db}$ are the standard deviations quoted above. The trend of rapidly increasing $Q_{0}$ with $D$ is not consistent with the saturation of $\Omega_{0}$ with $D$ observed in other experiments which, however, spanned a range of $D$ three to four times larger than in this study. $1-3,5$

Figure 3 shows the average values of $Q_{0}$ at each $D$ with the standard deviations for $Q_{0}$ shown vertically, and the $15 \%$ experimental uncertainty in $D$, horizontally. The curves $D, D^{\prime}$ and $D^{\prime \prime}$ from Fig. 2 are also given. A straight line (which must pass through $Q_{0}=0, D=0$ ) can also be drawn for a reasonable fit to the data of Fig. 3 (solid line E). It may be seen that in Eq. (3), for $\mathrm{K}_{2} \mathrm{D}<\dot{1}$, the term in parenthesis may be approximated by $\mathrm{K}_{2} \mathrm{D}$. Therefore, $Q_{0}(t) \approx K_{1} D$ in which $K_{1}$ defines the maximum slope of Eq. (3), that is, where $D$ is very small. The slope of the stralght line in Fig. 3 is $0.73 \times 10^{-9} \mathrm{cal} / \mathrm{rad}-\mathrm{g}$ compared with Jenks and Bopp's value of $\mathrm{K}_{1}=1.4 \times 10^{-9} \mathrm{cal} / \mathrm{rad}-\mathrm{g}$.

The method used to determine the activation energy $\mathrm{E}$ of the annealing process is described by Damask and Dienes. ${ }^{9}$ Temperature is increased at a constant rate $\alpha$ until a certain defect concentration is reached at $T$. The procedure is repeated for other values of $\alpha$, the final state always being the same. In this experiment, the final state was zero stored energy $(Q=0)$ at which point $T=T_{F}$, the temperature at the end of the exotherm: 


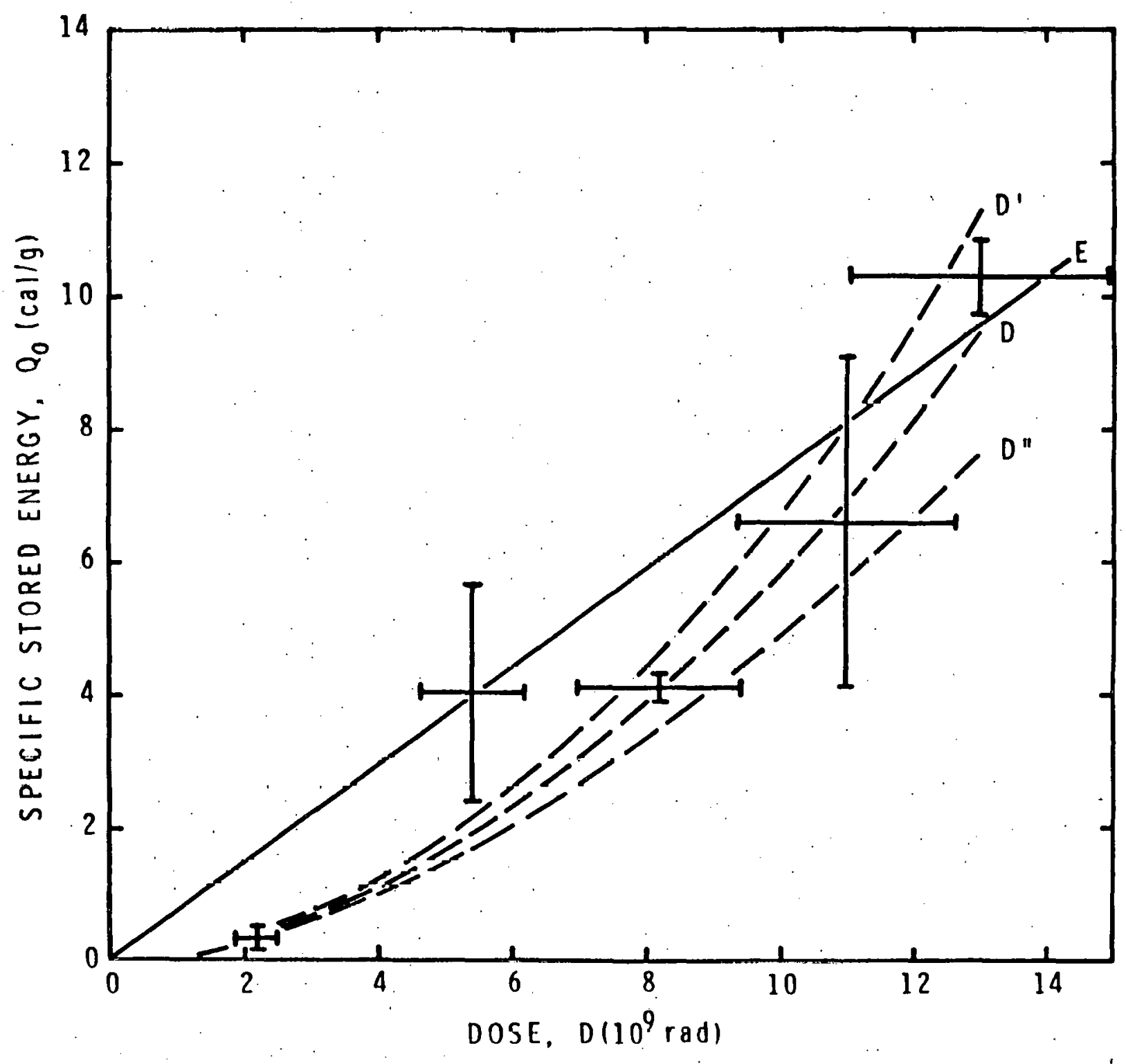

Figure 3. Specific stored energy vs. dose in WIPP salt. Average values of $Q_{0}$ are given with the standard deviations shown vertically, and the -0 15\% uncertainty in $D^{\circ}$ horizontally. Curves $D, D^{\prime}$ and $D^{\prime \prime}$ are repeated from Fig. 2. 
The rate of change of the defect concentration for a single activated process of constant activation energy $E$ is given by ${ }^{9}$

$$
\frac{d n}{d T}=-\frac{F(n) K_{0} e^{-E / R T}}{\alpha}
$$

in which $R$ is the gas constant, $K_{0}$ the pre-exponential constant, and $F(n)$ is any continuous function of $\mathrm{n}$, the fractional concentration of defects. For E/RT >> 1, which is supported by Jenks and Bopp's value of $E=38.9 \mathrm{kcal} / \mathrm{mole},{ }^{3}$ one gets

$$
\int_{n_{0}}^{n} \frac{d n}{F(n)}=-\frac{K_{0} R_{f}^{2} e^{-E / R T_{f}}}{\alpha E} .
$$

At identical values of $n$, the integral is a constant. Hence, running experiments for several values of $\alpha$ permits $E$ to be determined from the slope of a plot of $\ln \frac{\mathrm{T}_{\mathrm{f}}^{2}}{\alpha}$ vs. $\frac{1}{\mathrm{~T}_{\mathrm{f}}}$. This has been done for $\alpha=10,20,40$ and $80 \mathrm{k} / \mathrm{min}$, and for all doses except $D=2.2 \times 10^{9}$ rad for which $\mathrm{T}_{f}$ data were inadequate, the DSC-2 signal being too small at this low level of $Q_{0}$.

The results are plotted in Fig. 4. Lines $A, B, C$ and $D$ represent the highest through the lowest value of $D$ in that order. Slopes $(E / R)$ for $B, C$ and $D$ are approximately equal, yielding an activation energy in the range 27.7-29.1 kcal/mole; line A gives $39.4 \mathrm{kcal} / \mathrm{mole}$. It is not known why the most highly dosed sample yields the highest $\mathrm{E}$ value. The average of the four values is represented by line $\mathrm{E}(31.1 \mathrm{kcal} / \mathrm{mole})$, and the $5.6 \mathrm{kcal} / \mathrm{mole}$ standard deviation by $E^{\prime}$ and $E^{\prime \prime}$. Jenks and Bopp's value of $38.9 \mathrm{kcal} / \mathrm{mole}$ is their best "eyeball". fit for three different salt specimens, both pure and impure. ${ }^{3}$ Taken individually, their two lyons salt specimens gave 39.8 and 


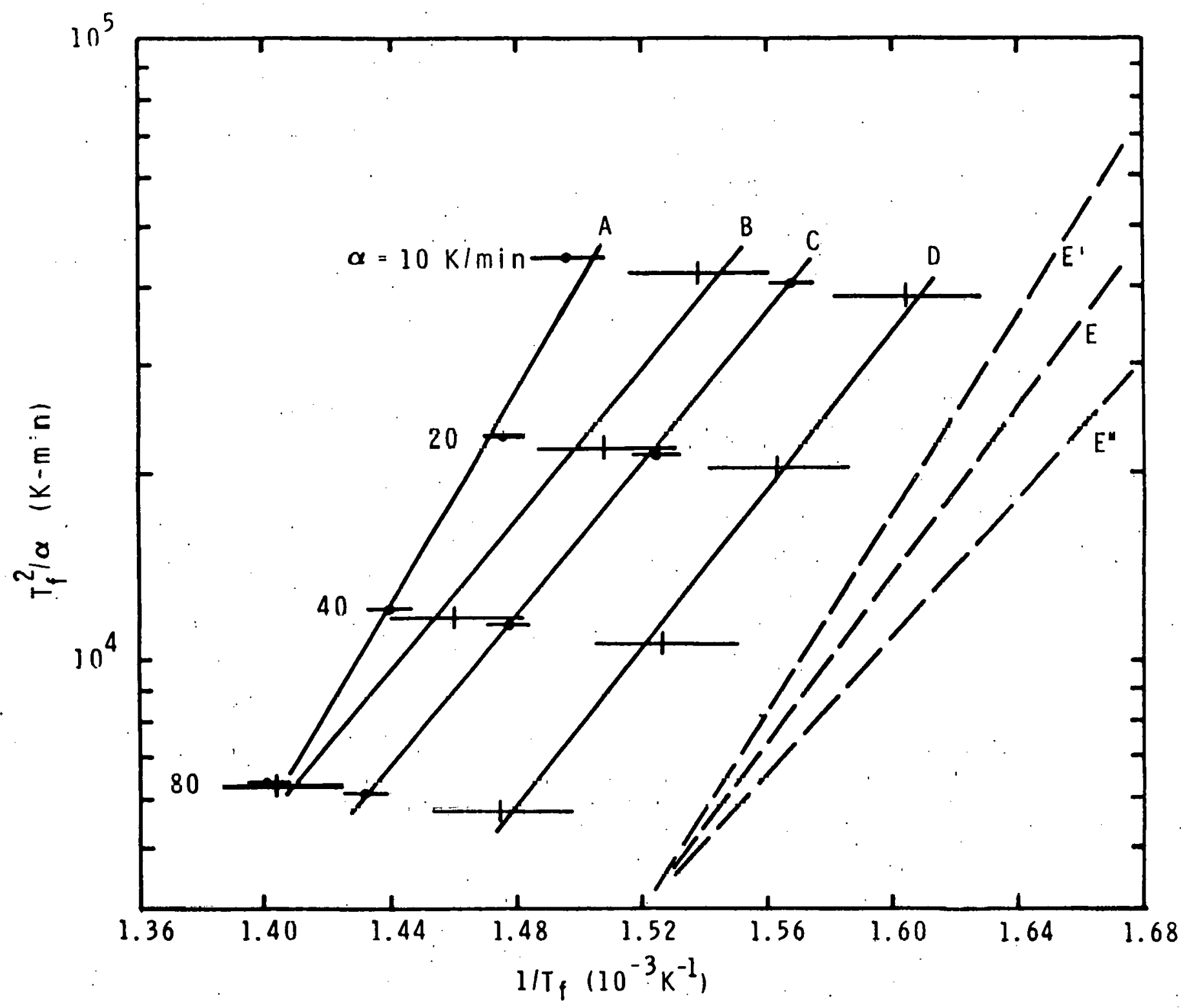

Figure 4.

Activation energy from slope of $\ln \frac{\mathrm{T}_{\mathrm{f}}^{2}}{x} \mathrm{vs} \cdot \frac{1}{\mathrm{~T}_{\mathrm{f}}}$. The scan rate for each horizontal set of four datum points is given at the left. The values of $\mathrm{E}$ in $\mathrm{kcal} / \mathrm{mole}$ and $D$ in rad are, respectively: (A) $39.4 ; 13 \times 10^{9}$, (B) $27.7 ; 11 \times 10^{9}$, (C) 27.9 ; $8.2 \times 10^{9}$, (D) $29.1 ; 5.4 \times 10^{9}$. The average activation energy is (E) $31.1 \pm 5.6$, $\left(E^{\prime}\right)$ and (E") representing the standard deviation. 'The positions of $E, E^{\prime}$ and $E^{\prime \prime}$ are arbitrary; only the slones are meant to be represcnted. 
$40.5 \mathrm{kcal} / \mathrm{mole}$, while their pure Harshaw salt gave $33.4 \mathrm{kcal} / \mathrm{mole}$. These average to $37.9 \pm 3.9 \mathrm{kcal} / \mathrm{mole}$, somewhat different fxom their "eyeball" value. These values, while not stated by Jenks and Bopp, may be deduced from p. 83 of their report. It should be noted that the samples they used for determination of activation energy fell in the higher range of stored energy $(7.5-13.1 \mathrm{cal} / \mathrm{g})$ and, therefore, their average $\mathrm{E}$ value is consistent with the $39.4 \mathrm{kcal} / \mathrm{mole}$ found for my most highly dosed sample.

Jenks and Bopp ${ }^{3}$ and Lidiard ${ }^{10}$ agree that the kinetics of the annealing process is zero order, an unusual circumstance. This could not be confirmed in the present experiment. Isothermal annealing experiments are planned which will determine the order and will be reported later. Zero order means $\gamma=0$ in the rate equation

$$
\frac{d n}{d t}=-K_{0} n^{\gamma} e^{-E / R T}
$$

$\mathrm{n}^{\gamma}$ is, of course, $\mathrm{F}(\mathrm{n})$ of Eqs. (4) and (5). Hence, Eq. (5) becomes ,

$$
n_{0}=\frac{K_{0} R T_{f}^{2} e^{-E / R T} f}{\alpha E},
$$

since $n=0$ (zero defect concentration at the final temperature $T_{f}$ ). From Eq. (7), one can determine the errors in $1 / T_{f}$ and $T_{f}^{2} / \alpha$ of Fig. 3 due to the variation in $n_{0}$ as indicated by the standard deviation of $Q_{0}$ (Fig. 3 ):

$$
\frac{d\left(1 / T_{f}\right)}{1 / T_{f}}=-\frac{d Q_{o}}{Q_{O}} \frac{1}{\left(2+E / R T_{f}\right)}
$$

and

$$
\frac{d\left(T_{f}^{2} / \alpha\right)}{T_{f}^{2} / \alpha}=\frac{d Q_{0}}{Q_{O}} \frac{1}{\left(1+E / 2 R T_{f}\right)}
$$


where $d Q_{0} / Q_{0}$ has been substituted for $d n_{0} / n_{0}$. These errors are shown in Fig. 4 as horizontal and vertical bars, respectively, unless the error in $\mathrm{T}_{\mathrm{f}}^{2} / \alpha$ is too small to be shown except by the datum point itself.

\section{Conclusions}

WIPP salt from the ERDA-9 drill hole (depths 741.3 and $796.0 \mathrm{~m}$ ) in the Carlsbad, New Mexico area has been irradiated at $363 \mathrm{~K}$ by $1.3 \mathrm{MeV}$ gamma radiation from a 10 Mrad/h co ${ }^{\hbar n}$ source. The specific stored energy $Q_{0}$ of samples dosed to $2.2,5.4$, 8.2, 11 and $13 \times 10^{9}$ rad has been measured on a Perkin-Elmer differential scanning. calorimeter by constant-rate temperature scans $(80 \mathrm{~K} / \mathrm{min})$ to $800 \mathrm{~K}$. The levels of $Q_{0}$ agree generally with those found by Jenks and Bopp for other irradiated salts. ${ }^{3} Q_{0}$ may be represented by the empirical relation, $1 \mathrm{n} 0_{0}(\mathrm{cal} / \mathrm{g})=(-40.6 \mp$ $2.6)+(1.84 \pm 0.12) \mathrm{lnD}(\mathrm{rad})$. This functional dependence does not agree with the results of Jenks and Bopp, particularly since it does not predict the expected saturation of stored energy with dose, but the dose range of this experiment was more restricted than theirs. Activation energy of the annealing process, measured by temperature scans of $10,20,40$ and $80 \mathrm{k} / \mathrm{min}$, was $31.1 \pm$ $5.6 \mathrm{kcai} / \mathrm{mole}$. For samples of comparable stored energy, Jenks and Bopp's value of $E$ agrees quite well with mine. In view of the general agreement on stored energy levels and activation energy, the criteria for safe storage of nuclear waste, as described by Jenks and Bopp, are satisfied, i.e., there appears to be no danger of the stored energy being released quickly in a nuclear waste repository of bedded salt, nor could serious consequences result from such a release by some unforeseen mechanism. Future work is planned to determine the kinetic order of the annealing process. 


\section{References}

1. J. D. Blomeke, et al., Oak Ridge National Laboratory Report No. ORNL-TM-3403, June 1971.*

2. G. H. Jenks and C. D. Bopp, Oak Ridge National Laboratory Report No. ORNLTM-4449, January 1974.*

3. G. H. Jenks and C. D. Bopp, Oak Ridge National Laboratory Report No. ORNL5058, October 1977.*

4. K. Kobayashi, Phy. Rev. 102, 348 (1956).

5. E. K. Zavadovskaya and A. V. Kuz'mina, Soviet Phys. Solid State 6 , 2677 (1965) .

6. J. M. Bunch and E. Pearlstein, Phys. Rev. 181, 181 (1969).

7. G. Dreschhoff, Modern Geology 4 , 29 (1973). In German.

8. D. W. Powers, et al., Ed., Sandia Laboratories Report No. SAND 78-1596, Vol. 1, August 1978, Fig. 2-10. *

9. A. C. Damask and G. J. Dienes, Point Defects in Metals (Gordon and Breach, New York, 1963), Chap. 3, p. 148.

10. A. B. Lidiard, Phil. Mag. A 39, 647 (1979).

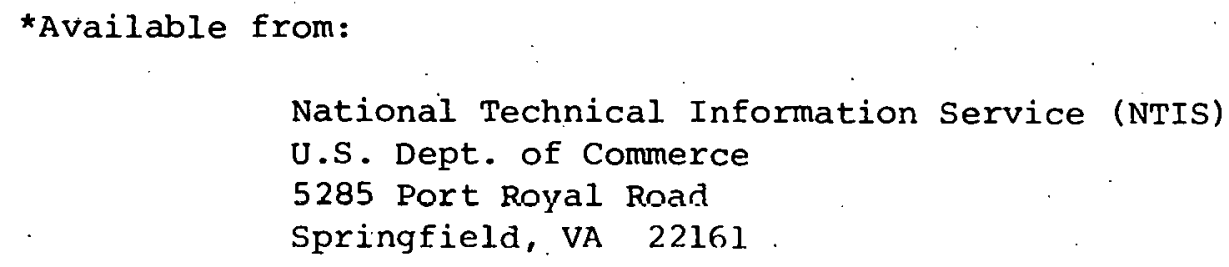


Distribution:

U.S. Department of Energy, Headquarters

Office of Nuclear waste Management

Washington, DC 20545

Eugene F. Beckett, Project Coordinator (WIPP) (1)

Colin A. Heath, Director, Division of Waste Isolation

Sheldon Myers

Raymond G. Romatowski

R. Stein

Carl L. Cooley

U.S. Department of Energy, Albuquerque Operations

P.O. Box 5400

Albuquerque, NM 87185

D. T. Schueler, Manager, WIPP Project Office

R. Rudelpli, Actiny Depily Mainayes, WIPP Psujecl orfice

G. Dennis, Director, Public Affairs Division

S. C. 'laylur, C\&TI Division (for Public Reading Rooms)

U.S. Department of Energy

Carlsbad WIPP Project Office

Room 113, Federal Building

Carlsbad, NM 88220

U.S. Department of Energy

c/o Battelle

Office of Nuclear waste Isolation

505 King Avenue

Columbus, $\mathrm{OH} \quad 4.32 \mathrm{n}$

Jeff 0 . Neff

Battelle Memorial Institute

Office of Nuclear waste Isolation

505 King Avenue

Columbus, $\mathrm{OH} \quad 43201$

Neil Carter, General Manager

wayne Carbiner

R. Robinson

J. F. Kircher

D. Moak

Westinghouse Electric Corporation P.O. Box 40039

Albuquerque, NM 87196

R. C. Mairson

National Academy of Sciences, WIPP Panel

Thomas H. Pigford, Member

Department of Nuclear Engineering

University of California

Berkeley, CA 94720 
Roger W. Staehle, Member

Dean, Institute of Technology

University of Minnesota

Lind $\mathrm{Hall}$

Minneapolis, MN 55455

John W. Winchester, Member

Department of Oceanography

Florida State University

Tallahassee, FL 32306

D'Arcy A. Shock; Consultant

23.3 Virginia

Ponca City, OK 74601

John T. Holloway, Executive Secretary

2101 Constitution Avenue, NW

Washington, DC 20418

Dr. Bruno Giletti, Co-Chairman

Department of Geological sciences

Brown University

Providence, Rhode Island

Paul W. Levy

Physics Department

Brookhaven National Laboratory

Associated Universities, Inc.

Upton, Long Island, NY 11973

D. E. Large

U.S. Department of Energy

Research \&. Technical Support Division

P. O. Box E

Oak Ridge, TN. 37830

Los Alamos Scientific Laboratory

Los Alamus, NM 87545

Attn: T. K. Keenan, $\mathrm{H}-7$.

Sandia Internal:

3310 W. D. Burnett

3313 A. L. Stanley

3141 T. L. Werner (5)

3151 W. L. Garner, for DOE/TIC (Unlimited Release) (3)

3154-3 R. P. Campbell, for DOE/TIC (25),

4500 E. H. Beckner

4510 W. D. Weart

4511 W. D. Weart (Acting)

4511 G. E. Barr

4512 T. O. Hunter.

4512 M. A. Molecke (5)

4540 M. L. Kramm

4541 L. W. Scully 
4542 Sandia WTPP Central Files (2)

4530 R. W. Lynch

4537 L. D. Tyler

4538 R. C. Lincoln

5100 F. L. Vook

Attn: 5110 R. T.. Schwoebel

5130 G. $A$. Siamara

5150 J. E. Schirber

5112 P. S. Peercy

5112 G. W. Arnold

5510 D. B. Hayes

5511 G. R. Hadley

5511 D. L. McVey

5531 L. D. Bertholf

5532 B. M. Butcher

5800 R. A rinasson

$$
\begin{array}{lll}
\text { Attn: } & 5810 & \text { R. G. Kepler } \\
& 5830 & \text { M. J. Davis } \\
& 5840 & \text { N. J. Magnani }
\end{array}
$$

5812 C. J. Northrup

5820 R. E. Whan

Attn: 5821 N..E. Brown

5822 K. H. Eckelmeyer

5823 J. A. Borders

5824 J. N. Sweet (4)

$5824^{\circ}$ M. Moss (4)

5824 J. E. McCreight

5824 J. A. Koski

8266 E. A. Aas (2) 


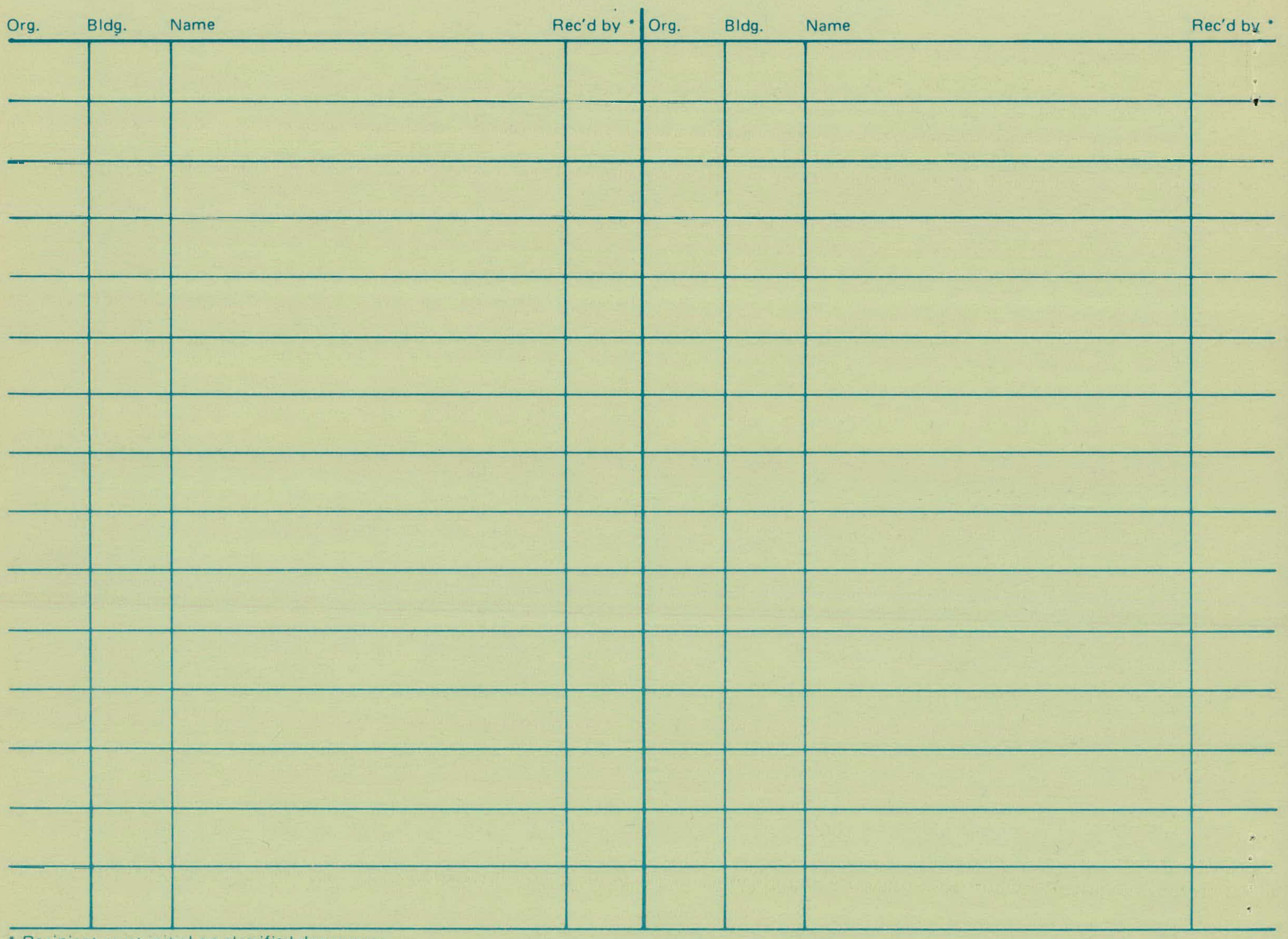

- Recipient must initial on classified documents. 